\title{
Immunoelectrophoretic analysis of the porcine zona pellucida
}

\author{
A. G. Sacco, E. C. Yurewicz and S. Zhang* \\ Wayne State University School of Medicine, Department of Gynecology and Obstetrics, \\ The C. S. Mott Center for Human Growth and Development, 275 E. Hancock Avenue, Detroit, \\ Michigan 48201, U.S.A.
}

\begin{abstract}
Summary. Antigens of the porcine zona pellucida were evaluated by 2-dimensional and line immunoelectrophoretic techniques. Zona antigen preparations studied included heat-solubilized isolated zonae pellucidae (SIZP), a purified $60000 \mathrm{M}_{\mathrm{r}}$ glycoprotein (PPZA, purified pig zona antigen), and two fractions of this $60000 \mathrm{M}_{\mathrm{r}}$ zona component which had been exposed to SDS (ZP3-E1C and ZP3-E2C). Antisera were raised to intact zonae pellucidae (IZP), SIZP and PPZA.

Collectively, electrophoretic data revealed that the porcine zona system is antigenically complex with each zona antiserum tested detecting numerous antigens in the various zona preparations. These antigens, however, all had similar electrophoretic mobilities, and this limited the resolution of these techniques. The $60000 \mathrm{M}_{\mathrm{r}}$ pig zona macromolecule (ZP3) appeared to be the most immunogenic of the three major pig zona glycoproteins since antisera prepared against IZP or SIZP reacted primarily with this component. However, the $60000 \mathrm{M}_{\mathrm{r}}$ component does share antigenic determinants with the other major zona glycoproteins as revealed by cross-reactions of the antisera with the various zona preparations. Electrophoretic studies also suggested that the various zona antisera could distinguish, with different degrees of sensitivity, multiple antigenic determinants on the individual zona macromolecules. These studies also indicated that SDS treatment of zona glycoproteins does alter the antigenicity of the macromolecule, both with respect to the total number and individual identity of antigens detected.
\end{abstract}

\section{Introduction}

Two-dimensional polyacrylamide gel electrophoresis (2-D PAGE) of pig zonae has revealed the presence of three major components (Subramanian, Yurewicz \& Sacco, 1981; Sacco, Yurewicz, Subramanian \& DeMayo, 1981; Dunbar, Liu \& Sammons, 1981; Hedrick \& Wardrip, 1981) with average molecular weights $\left(M_{r}\right)$ of 55 000-60 000, 65 000-70 000 and 90000-92000. Each of these components resolves into a family of charge isomers in the isoelectric focussing dimension with molecular weights of individual members increasing towards the acidic end of the isoelectric focussing gel in a manner which is highly characteristic of glycoproteins. The three families each possess a unique polypeptide backbone chain. However, individual charge isomers within a particular family have the same polypeptide chain but differ in the primary structure of their carbohydrate moieties (Hedrick \& Wardrip, 1981). The molecular complexity of the zona is further emphasized in immunochemical studies which not only reveal that numerous antigens are associated with this structure but also indicate significant variations in immunological response dependent upon the method of zona solubilization used (Dunbar \& Raynor, 1980; Wood \& Dunbar, 1981).

* Present address: Institute of Reproductive Immunology, Jinan University, Canton, China. 
We have isolated from pig zonae (Subramanian et al., 1981) a purified porcine zona antigen (PPZA), which is not homogeneous, but contains mostly the $60000 \mathrm{M}_{\mathrm{r}}$ glycoprotein family (ZP3). It resolves into $>20$ charge isomers and is free of the other two major families $\left(Z P 1, M_{r}=92000\right.$; $Z P 2, M_{r}=70000$ ). This PPZA has been isolated in aqueous bufffers under non-dissociating conditions and without the cleavage of disulphide bonds, and should therefore possess a molecular configuration closely resembling that of the native molecule within the intact zona.

The purpose of the present investigation was to evaluate antigens associated with the porcine zona pellucida through the use of various electrophoretic techniques. The availability of PPZA and its respective antisera permitted an antigenic analysis of the porcine zona with respect to an identifiable and characterized molecular component (ZP3) and this study therefore differs significantly from earlier investigations (Dunbar \& Raynor, 1980; Wood \& Dunbar, 1981).

\section{Materials and Methods}

\section{Antigen preparation}

Four different preparations of solubilized porcine zonae pellucidae were used as antigens in electrophoretic studies: (1) SIZP (heat-solubilized isolated zonae pellucidae), (2) PPZA (purified pig zonae antigen), (3) ZP3-E1C, and (4) ZP3-E2C.

Zonae encased pig eggs and/or isolated zonae were obtained essentially as described by Dunbar \& Raynor (1980) and as modified by Subramanian et al. (1981) and Sacco et al. (1981). Briefly, quantities of 500 frozen-thawed pig ovaries, obtained from a local slaughterhouse, were homogenized in a commercial meat grinder in $50 \mathrm{~mm}$ - Tris- $\mathrm{HCl}$ buffer, $\mathrm{pH} 8 \cdot 0$, and isolated oocytes were collected by sieving the ovarian homogenate through nylon monofilament screens (Tetko, Inc.) of decreasing pore size. Isolated zonae were acquired from the zonae-encased oocyte preparations by homogenization of the oocytes in a Potter-Elvehjem homogenizer and collection of the empty zonae on a $50 \mu \mathrm{m}$ screen. The isolated zonae were transferred to $100 \mathrm{ml} 20 \mathrm{mM}$-Tris buffer, pH 8.0, and washed for $60 \mathrm{~min}$ using a magnetic stirrer. The washed zonae were again concentrated by collection on the $50 \mu \mathrm{m}$ screen and then transferred into a $10-20 \mathrm{ml}$ volume of 20 mM-Tris buffer. SIZP preparations were obtained by heating isolated zonae in a water bath at $73^{\circ} \mathrm{C}$ for $20 \mathrm{~min}$; after centrifuging $(27000 \mathrm{~g}, 15 \mathrm{~min})$ the supernates were stored frozen at $-20^{\circ} \mathrm{C}$. SIZP preparations for use in 2-dimensional (2-D) immunoelectrophoretic studies were concentrated by ultrafiltration (Amicon) to approximately $2-\mathrm{ml}$ volumes before electrophoresis. Protein concentrations of the SIZP preparations were determined by the method of Lowry, Rosebrough, Farr \& Randall (1951) using bovine serum albumin as standard.

PPZA was prepared using methods of gel filtration and ion-exchange chromatography similar to those indicated by Subramanian et al. (1981). The major feature of this protocol is its use of only aqueous (non-dissociating) buffers and the absence of conditions causing disulphide bond cleavage. SIZP preparations, representing $3500-4000$ ovaries, were pooled, centrifuged $(27000 \mathrm{~g}$, $15 \mathrm{~min}$ ) and concentrated by ultrafiltration. The sample ( $7-8 \mathrm{ml}, \sim 20 \mathrm{mg}$ protein) was applied to a column $(1.9 \times 113 \mathrm{~cm})$ of Bio-Gel A5M resin and eluted with $20 \mathrm{mM}-\mathrm{Tris}$ buffer, pH 8.0. Material with zona antigen activity, as monitored by radioimmunoassay (RIA) (Subramanian et al., 1981), eluted as an aggregate in the void volume. Pooled fractions of this material ( $\sim 7 \mathrm{mg}$ protein) were applied directly to a column $(0.9 \times 54 \mathrm{~cm})$ of DEAE Bio-Gel and, following passage of $90 \mathrm{ml} 20$ mM-Tris buffer, the active antigen was eluted by application of a linear salt gradient $(0-0.5 \mathrm{M}-\mathrm{NaCl}$ in 20 mm-Tris, $\mathrm{pH} \mathrm{8.0)}$. Pooled fractions of zona antigen-active material from this column were concentrated by ultrafiltration and are referred to as PPZA. Its purity was assessed by 2-D PAGE and gel photographs of a previous preparation of this isolated pig zona glycoprotein component have been published (Subramanian et al., 1981; Sacco et al., 1981).

Two additional preparations of ZP3 were studied and differed primarily from the above PPZA by the inclusion of SDS in the purification protocol and by the homogeneity of the product 
obtained. SIZP obtained from 3500 ovaries was treated with $1 \%$ SDS for 30 min at $60^{\circ} \mathrm{C}$, a treatment which resulted in loss of $85 \%$ of original zona antigen activity as measured by RIA. The sample was then subjected to gel filtration in $50 \mathrm{mM}$-Tris- $\mathrm{HCl}$ buffer, $\mathrm{pH} 8 \cdot 0$, containing $0 \cdot 1 \%$ SDS. The fractions enriched in ZP3, as established by RIA and SDS-PAGE, were pooled and further fractionated by adsorption chromatography in $10 \mathrm{~mm}$-phosphate buffer, $\mathrm{pH} 6.8$, containing $0 \cdot 1 \%$ SDS. Two fractions of ZP3 were obtained by this chromatographic step and designated ZP3E1C and ZP3-E2C. Both preparations were homogeneous as judged by SDS-PAGE and 2-D PAGE : SDS-PAGE yielded a single diffuse band at $M_{r}=60000$ for each fraction, but 2-D PAGE clearly demonstrated a difference in relative ratios of charge isomers with the ZP3-E2C fraction being highly enriched in charge isomers of more neutral $\mathrm{pI}$ and essentially devoid of the more acidic isomers relative to ZP3-E1C. Following removal of SDS by ion pair extraction (Henderson, Oroszlan \& Konigsberg, 1979) the samples were used in 2-D immunoelectrophoretic investigations.

\section{Preparation of antisera}

Three different antisera to pig zonae pellucidae were used. All were produced in male rabbits by an immunization regimen similar to that described by Vaitukaitis, Robbens, Nieschlag \& Ross (1971) which consisted of multiple intradermal injections of immunogen applied with Freund's adjuvant. The preparation, properties and zona specificity of antisera to intact pig zonae pellucidae (anti-IZP) and PPZA (anti-PPZA) have been described previously (Sacco \& Palm, 1977; Palm, Sacco, Syner \& Subramanian, 1979; Subramanian et al., 1981; Sacco et al., 1981). Anti-IZP serum required absorption with pig follicular fluid to render it specific to the zona. This antiserum presumably represented zona antibodies prepared against antigens in their native unaltered condition within the intact zona. The anti-PPZA serum used was produced against the PPZA preparation obtained under non-dissociating conditions. The third antiserum was developed against heat-solubilized isolated zonae pellucidae (anti-SIZP) prepared as described above since heat-solubilization represents one of the mildest and least disruptive methods for obtaining zona components in solution. The SIZP $(500 \mu \mathrm{g})$ was given in 3 injections 1 week apart, and a 4 th injection 10 weeks later (total dosage $=2 \mathrm{mg}$ ). The first application was given with Freund's complete adjuvant and all others with incomplete adjuvant. All antisera were evaluated for antizona activity by RIA (Palm et al., 1979; Subramanian et al., 1981) and by formation of the precipitation layer on the outer surface of the zona after antibody treatment of zonae-encased oocytes (Sacco, 1981).

\section{Electrophoresis}

SDS-PAGE was conducted by the method of Laemmli (1970), using slab gels $(1.5 \mathrm{~mm})$ prepared with linear 5-15\% polyacrylamide gradients. Samples were dissolved in 62.5 mM-Tris$\mathrm{HCl}$ buffer, $\mathrm{pH} 6 \cdot 8$, containing $10 \%(\mathrm{v} / \mathrm{v})$ glycerol and $2 \%(\mathrm{w} / \mathrm{v}) \mathrm{SDS}$, and heated at $100^{\circ} \mathrm{C}$ for $2 \mathrm{~min}$ immediately before electrophoresis (non-reducing conditions). Treatment of SIZP or PPZA with SDS and heat, under the above conditions, in the presence of mercaptans, such as mercaptoethanol or dithiothreitol, resulted in total loss of all the original zona antigen activity. Under the nonreducing conditions employed, approximately $10 \%$ of the activity is retained.

2-D PAGE was conducted by the O'Farrell (1975) technique as modified by Garrels (1979). Radioiodination of PPZA and electrophoresis conditions as applicable to the zona system have previously been detailed (Sacco et al., 1981).

Two-dimensional immunoelectrophoresis methods used were based on those described by Laurell (1965) and Weeke (1973a). A $22 \times 80 \mathrm{~mm}$ gel strip composed of $0.7 \%$ agarose in $20 \mathrm{~mm}$ sodium barbital buffer, $\mathrm{pH} 8 \cdot 6$, was poured onto one end of a glass plate $80 \times 100 \mathrm{~mm}$ in size for first-dimension electrophoresis. A $4 \mathrm{~mm}$ sample well was cut into one end of this gel strip, the sample applied (4-52 $\mathrm{g}$ zona protein) and electrophoresis conducted for $3 \mathrm{~h}$ at $20^{\circ} \mathrm{C}$ and $90 \mathrm{~V}$, using 
a Gelman electrophoresis chamber. A $1 \%$ agarose gel in $20 \mathrm{~mm}$-barbital buffer, containing $2-8 \%$ antibody and $1 \%$ Triton-X100 (Bjerrum, 1977), was then poured over the remaining exposed surface of the glass plate. Electrophoresis in the second dimension was at $35 \mathrm{~V}$ and $20^{\circ} \mathrm{C}$ for $24 \mathrm{~h}$. Plates were washed, dried and stained with Coomassie blue according to Weeke (1973b).

The above procedure was modified by the substitution of SDS-PAGE for the first-dimension electrophoresis (SDS-PAGE immunoelectrophoresis). Quadruplicate lanes of each zona preparation tested by this procedure were electrophoresed simultaneously. Three of the sample lanes were used in reactions with antisera and the fourth was stained for protein. SDS-PAGE was conducted in gel slabs as described above, the appropriate sample lanes $(10 \times 80 \mathrm{~mm})$ were cut from the slab and, after a 15 min wash in distilled water to remove unbound SDS, the polyacrylamide gel strip was placed across the bottom of a glass plate $(80 \times 100 \mathrm{~mm})$ approximately $10 \mathrm{~mm}$ from the edge. Antibody-containing gel was poured above the gel strip, $0.7 \%$ agarose in 20 mM-sodium barbital buffer was poured on the glass plate below the gel strip to serve as a wick support and electrophoresis was carried out as described above for $24 \mathrm{~h}$ at $35 \mathrm{~V}$.

Tandem 2-D immunoelectrophoresis was performed according to Kroll (1973a). Two $4 \mathrm{~mm}$ sample wells with an intercentre distance of about $8 \mathrm{~mm}$ were cut into one end of a gel strip prepared as described above and the samples were applied. After 30-60 min to allow for sample diffusion, the wells were sealed with $0.7 \%$ agarose and first- and second dimension electrophoresis was conducted as previously indicated.

Line immunoelectrophoresis was patterned after methods described by Kroll (1973b). A $2 \times 65$ $\mathrm{mm}$ trough was cut into a gel strip and filled with sample $(30-87.5 \mu \mathrm{g}$ zona protein) contained in $0.7 \%$ agarose. Various antibody-containing gels were poured adjacent to the gel strip as described above and electrophoresis was carried out at $35 \mathrm{~V}$ and $20^{\circ} \mathrm{C}$ for $24 \mathrm{~h}$.

\section{Results}

\section{Electrophoretic characteristics of zona antigens}

Before large scale 2-D immunoelectrophoretic studies, numerous tests were performed under different antigen-antibody concentrations and electrophoretic conditions to evaluate the characteristics of and establish optimal parameters for the zona system.

Staining for protein immediately after electrophoresis in the first dimension indicated that zona proteins consistently migrated in agarose as a generalized smear. No distinct protein bands were resolved over the range of electrophoresis times $(2-6 \mathrm{~h})$ studied.

The most noticeable feature of the zona system following second-dimension electrophoresis of zona antigens into antibody-containing gels was the similar electrophoretic mobilities of all antigens recognized by the immobilized zona antibodies, regardless of length of first-dimension electrophoresis time. Thus, a characteristic of zona antigens as evaluated by $2-\mathrm{D}$ immunoelectrophoresis is the stacking of precipitin arcs representing the individual zona antigen-antibody reactions.

Under identical electrophoretic conditions, increasing antigen concentration against a constant antibody concentration resulted in higher precipitin arcs, better completion of some precipitin arcs and, generally, an improvement in overall resolution (P1.1, Fig. 1). In contrast, under the identical electrophoretic conditions, a constant antigen concentration versus an increasing antibody concentration resulted in a decrease in precipitin arc height and generally a decrease in arc resolution (Pl. 1, Fig. 2). Increasing electrophoresis times for the first dimension had no significant effect on improving separation of the individual zona antigen-antibody systems and, in contrast to an earlier report (Dunbar \& Raynor, 1980), had no significant effect on increasing the completeness of precipitin arcs (P1. 1, Figs 3-5). It did result, however, in the precipitin arcs, in toto, migrating closer to the anode and presenting a slightly broader pattern with a concurrent slight decrease in arc height (compare Pl. 1, Fig. 3 with Pl. 1, Figs 4 \& 5). Increasing electrophoresis time in the second 
dimension, with other conditions constant, resulted in increased precipitin arc height. On the basis of these data, the electrophoresis conditions and antigen-antibody concentrations indicated in the 'Materials and Methods' were selected.

\section{2-Dimensional immunoelectrophoresis}

Total numbers of precipitin arcs resolved by 2-D immunoelectrophoresis when each of the three antisera were reacted against each of the zona antigen preparations are summarized in Table 1. Gel photographs of the various reactions are presented in Pl. 1, Fig. 6; Pl. 2, Figs 7-12; Pl. 3, Figs 13 $\& 14$. For each antiserum, the largest number of precipitin arcs was resolved upon reaction with SIZP. However, all 3 antisera contained antibodies capable of reacting with components present in each of the zona preparations tested. The anti-PPZA serum produced more precipitin arcs when reacted against SIZP than against its homologous antigen. The reactions of anti-SIZP and antiPPZA sera with PPZA represented the only exceptions to the typical stacked zona precipitin arc pattern because 2 arcs $(a, b)$ consistently migrated slightly closer to the anode than did the remaining arcs (P1. 2, Fig. 10; P1. 3, Fig. 13).

Table 1. Precipitin arcs detected by 2-D immunoelectrophoresis when various rabbit anti-pig zonae pellucidae sera are reacted against different solubilized preparations of pig zonae pellucidae

\begin{tabular}{ccccc}
\hline & \multicolumn{4}{c}{ Zona antigen preparation } \\
\cline { 2 - 5 } $\begin{array}{c}\text { Antiserum } \\
\text { against }\end{array}$ & SIZP & $\begin{array}{c}\text { PPZA } \\
\text { (non-SDS-treated) }\end{array}$ & $\begin{array}{c}\text { ZP3-E1C } \\
\text { (SDS-treated) }\end{array}$ & $\begin{array}{c}\text { ZP3-E2C } \\
\text { (SDS-treated) }\end{array}$ \\
\hline IZP & 6 & 2 & 2 & $3^{*}$ \\
SIZP & $\mathrm{a}, \mathrm{b}, \mathrm{c}, \mathrm{d}, \mathrm{e}, \mathrm{f}$ & $\mathrm{e}, \mathrm{f}$ & $\mathrm{e}, \mathrm{f}$ & 4 \\
PPZA & $\mathrm{a}, \mathrm{b}, \mathrm{c}, \mathrm{d}, \mathrm{e}, \mathrm{f}, \mathrm{g}, \mathrm{h}$ & $\mathrm{a}, \mathrm{b}, \mathrm{c}, \mathrm{f}, \mathrm{gh})$ & $\mathrm{a}, \mathrm{b}, \mathrm{d}, \mathrm{f}$ & $\mathrm{a}, \mathrm{b}, \mathrm{d}, \mathrm{f}$ \\
$\mathbf{9}$ & $\mathrm{a}, \mathrm{b}, \mathrm{c}, \mathrm{d}, \mathrm{e}, \mathrm{f}, \mathrm{g}, \mathrm{h}, \mathrm{i}$ & $\mathrm{a}, \mathrm{b}, \mathrm{fg}), \mathrm{h}, \mathrm{i}$ & $\mathrm{a}, \mathrm{b}, \mathrm{d}$ & $\mathrm{a}, \mathrm{b}, \mathrm{d}, \mathrm{h}$ \\
\hline
\end{tabular}

IZP $=$ intact zona pellucida; SIZP $=$ heat-solubilized isolated zona pellucida; PPZA = purified pig zona antigen; $\mathbf{Z P}=$ zona pellucida.

* Total number of individual precipitin arcs could not be precisely identified using tandem 2-D immunoelectrophoresis due to consistent inadequately resolved precipitin arc patterns in the fusion area between samples.

$\dagger$ Remaining bands have no counterpart in SIZP.

\section{Tandem 2-dimensional immunoelectrophoresis}

The fusion of precipitin arcs formed when two zona samples were electrophoresed simultaneously into the same antiserum (tandem 2-D immunoelectrophoresis) was interpreted as designating common antigens shared by the two samples. The individual precipitin arcs detected are identified by lower case letters in the figures (Pl. 1, Fig. 6; Pl. 2, Figs 7-12; Pl. 3, Figs 13 \& 14) and the reactions from tandem studies are summarized in Table 1. Precipitin arcs were labelled on the basis of patterns obtained between antisera and SIZP since reactions with SIZP produced the most arcs. Patterns produced between each antiserum and the various ZP3 preparations (PPZA, ZP3-E1C, ZP3-E2C) were then compared to the respective SIZP pattern.

For anti-IZP serum 6 precipitin arcs (a-f) were identified in the reaction with SIZP (P1. 1, Fig. 6) and, two of these, ' $e$ ' and ' $f$ ', were common to each of the three ZP3 preparations (P1. 2, Figs 7 \& 8).

Anti-SIZP serum produced 8 precipitin arcs $(a-h)$ when reacted against SIZP (P1. 2, Fig. 9), 6 $(a, b, c, f,(g, h))$ of which were common to PPZA. Arcs ' $g$ ' and ' $h$ ' fused to form a single arc in the reaction between anti-SIZP and PPZA (Pl. 2, Fig. 10). The same four precipitin arcs (a, b, d, f) were common to the ZP3-E1C and ZP3-E2C preparations (PI. 2, Fig. 11). 
Nine precipitin arcs $(\mathrm{a}-\mathrm{i})$ were produced in the reaction between anti-PPZA serum and SIZP (P1. 2, Fig. 12). Six of these arcs (a, b, (f, g), h, i) were common to PPZA (Pl. 3, Fig. 13). Arcs 'f' and ' $g$ ' fused to form a single arc in the reaction between anti-PPZA serum and PPZA. Three and four

\section{PLATE 1}

Two-dimensional immunoelectrophoresis of heat-solubilized isolated pig zonae pellucidae (SIZP) into gels containing zona antibodies. First-dimension electrophoresis was from right to left (anode) and second-dimension electrophoresis from bottom to top (anode) as indicated by arrows in Fig. 1.

Fig. 1. Effect of varying antigen concentration on precipitin arc pattern, Wells A, B and C containing 21,14 and $7 \mu \mathrm{g}$ SIZP respectively. Antibody gel contains $2 \%$ anti-SIZP serum.

Fig. 2. Effect of varying antibody concentration on precipitin arc pattern. Each well contains $14 \mu \mathrm{g} \mathrm{SIZP}$ and samples were electrophoresed into 2,5 and $10 \%$ concentrations of anti-SIZP serum.

Fig. 3. Effect of antigen concentration on improvement in the completeness of some precipitin arcs. Right well contains $7 \mu \mathrm{g}$ SIZP, left well contains $42 \mu \mathrm{g}$ SIZP. Antibody gel contains $2 \%$ anti-SIZP serum. Electrophoresis was for $3 \mathrm{~h}$ at $90 \mathrm{~V}$ in the first dimension and for $24 \mathrm{~h}$ at $35 \mathrm{~V}$ in the second dimension. Note improved resolution and greater completeness of inner two arcs (arrows) in concentrated sample in left well.

Figs 4 \& 5. Electrophoresis of $42 \mu \mathrm{g}$ SIZP (Fig. 4) and $7 \mu \mathrm{g}$ SIZP (Fig. 5) for $6 \mathrm{~h}$ at $90 \mathrm{~V}$ in first dimension. Second-dimension electrophoresis was for $24 \mathrm{~h}$ at $35 \mathrm{~V}$ into $2 \%$ anti-SIZP serum. Increasing first-dimension electrophoresis time did not improve completeness of inner two precipitin arcs (arrows).

Fig. 6. Electrophoresis of $7 \mu \mathrm{g}$ SIZP into $3 \%$ anti-intact zonae pellucidae (IZP) serum. Firstdimension electrophoresis was for $3 \mathrm{~h}$ at $90 \mathrm{~V}$ and second-dimension electrophoresis was for 24 $\mathrm{h}$ at $35 \mathrm{~V}$. Six precipitin arcs (labelled a-f) were resolved. The precipitin arc labelled ' $a, b$ ' and the arc labelled ' $e$, $f$ ' each consist of two overlapping precipitin arcs although they are not resolved in the photograph.

\section{PLATE 2}

Two dimensional immunoelectrophoresis of various pig zonae pellucidae samples into gels containing zona antibodies. Electrophoresis conditions were identical for all figures: first dimension electrophoresis for $3 \mathrm{~h}$ at $90 \mathrm{~V}$ and second dimension electrophoresis for $24 \mathrm{~h}$ at $35 \mathrm{~V}$.

Fig. 7. Electrophoresis of PPZA ( $7 \mu \mathrm{g})$ into $3 \%$ anti-IZP serum. Two precipitin arcs, 'e' and 'f', are resolved.

Fig. 8. Electrophoresis of ZP3-E1C (5.25 $\mu \mathrm{g})$ and ZP3-E2C (5.25 $\mu \mathrm{g})$ into $8 \%$ anti-IZP serum. Two precipitin arcs (' $e$ ' and ' $f$ ') are resolved in the E1C pattern and 3 in the E2C pattern. Only two (' $e$ ' and 'f') of the latter could be identified from tandem-2D studies, the 3rd arc overlaps the ' $\mathrm{f}$ ' arc. The small arc over the sample well in the $\mathrm{E} 2 \mathrm{C}$ reaction is caused by residual sample remaining in the well at the initiation of second-dimension electrophoresis.

Fig. 9. Electrophoresis of SIZP $(7 \mu \mathrm{g})$ into $2 \%$ anti-SIZP serum. Eight precipitin arcs $(\mathrm{a}-\mathrm{h})$ are resolved.

Fig. 10. Electrophoresis of PPZA $(24.5 \mu \mathrm{g})$ into $2 \%$ anti-SIZP serum. Five precipitin arcs $(\mathrm{a}, \mathrm{b}$, c, $f,(g h))$ are resolved. Precipitin arc labelled ' $a$, b' consists of 2 overlapping precipitin arcs although these are not resolved in the photograph. Arcs ' $g$ ' and ' $h$ ', as established from tandem studies, fuse to form the single arc in this reaction which is labelled (gh).

Fig. 11. Electrophoresis of ZP3-E1C (5.25 $\mathrm{g})$ and ZP3-E2C $(5 \cdot 25 \mu \mathrm{g})$ into $2 \%$ anti-SIZP serum. The same 4 precipitin arcs $(a, b, d, f)$ are resolved in each reaction although the intensity of the ' $d$ ' and ' $f$ ' arcs is consistently greater in the E2C reaction. Precipitin arc labelled ' $a$, $b$ ' consists of two overlapping precipitin arcs although they are not resolved in the photograph.

Fig. 12. Electrophoresis of SIZP $(52 \mu \mathrm{g})$ into $2 \%$ anti-PPZA serum. Nine precipitin arcs (a-i) are resolved. 
PLATE 1

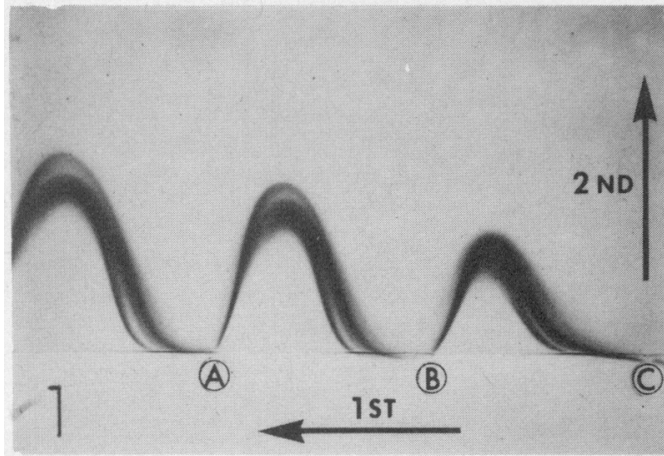

$10 \% \quad 5 \% \quad 2 \%$

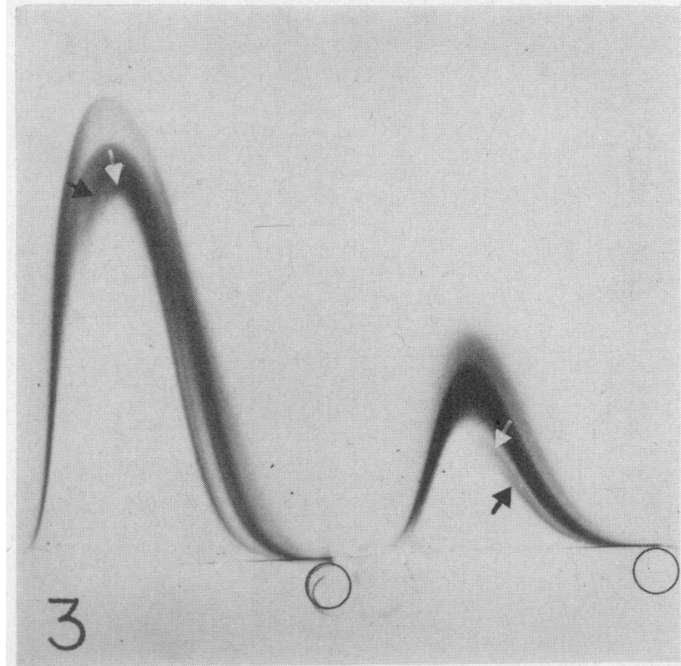

4
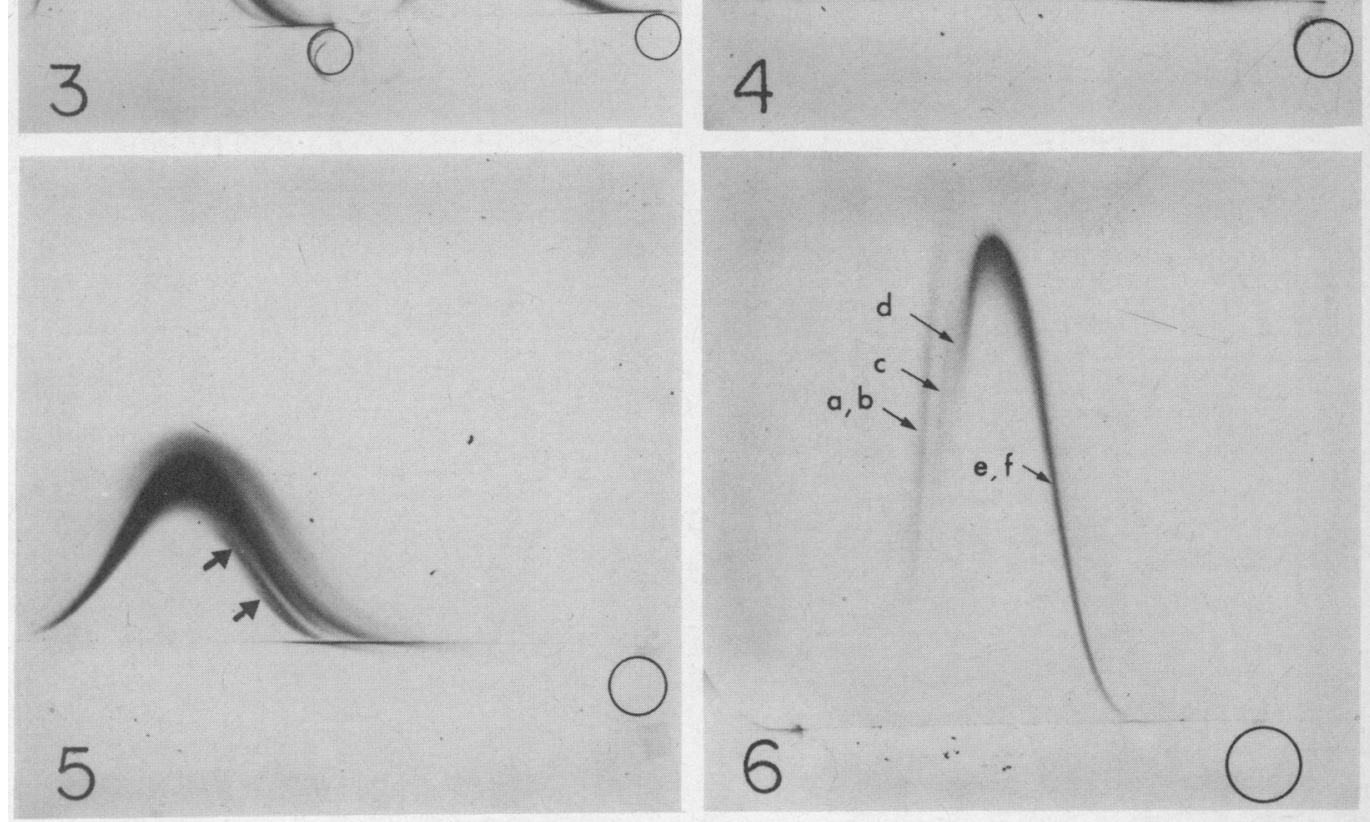

(Facing p. 26) 


\section{PLATE 2}

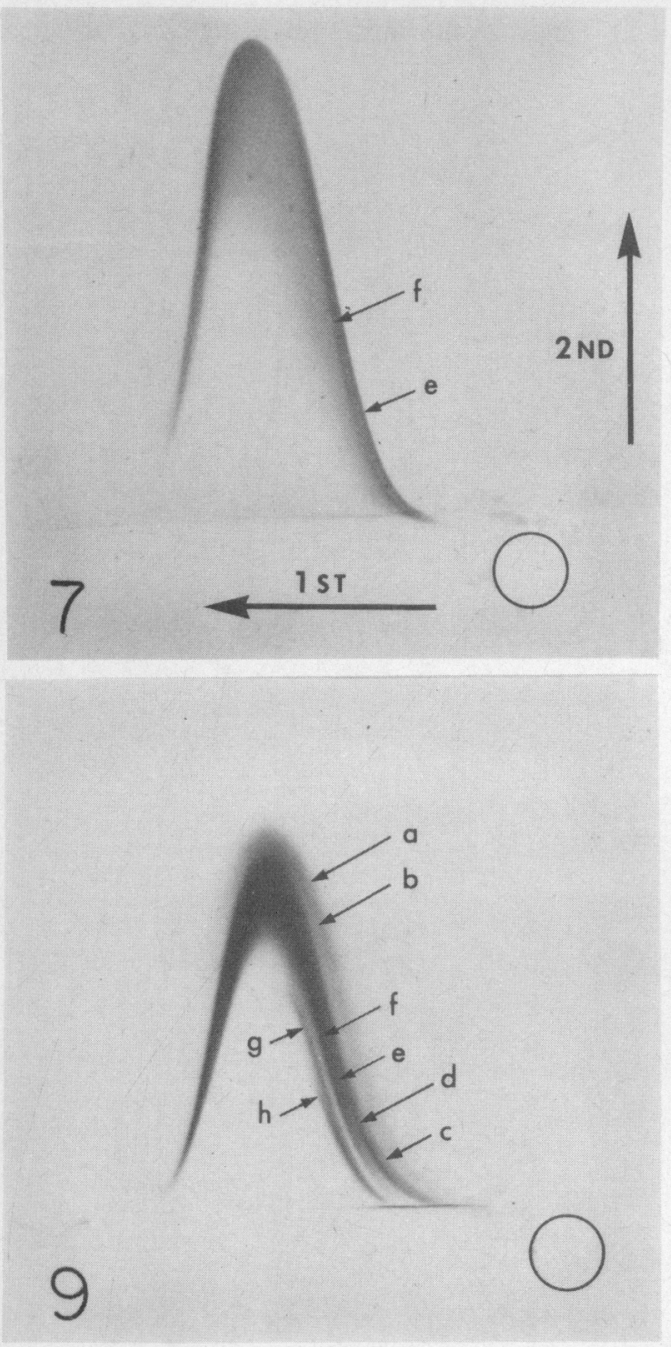

E1C

E $2 \mathrm{C}$

EIC

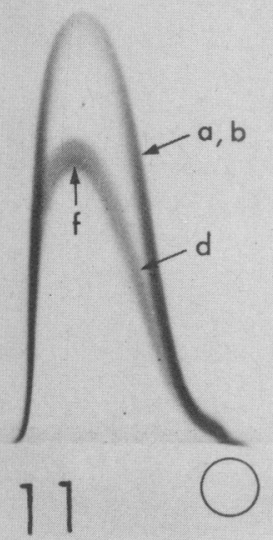

E2C

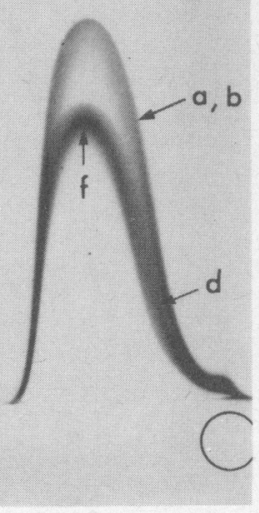

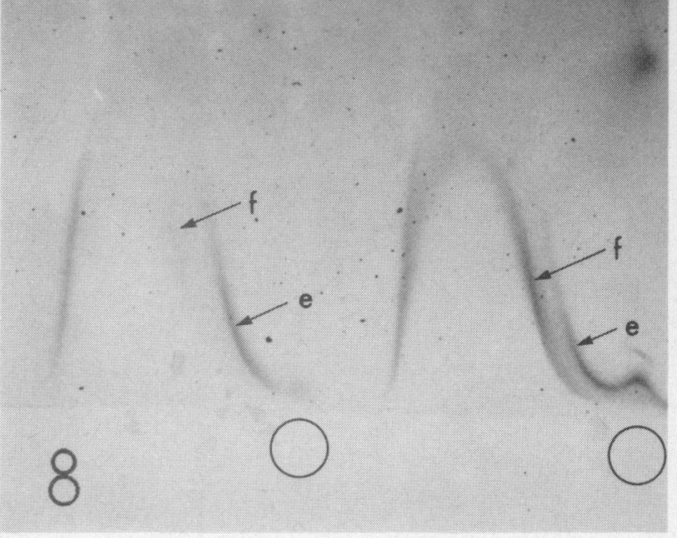

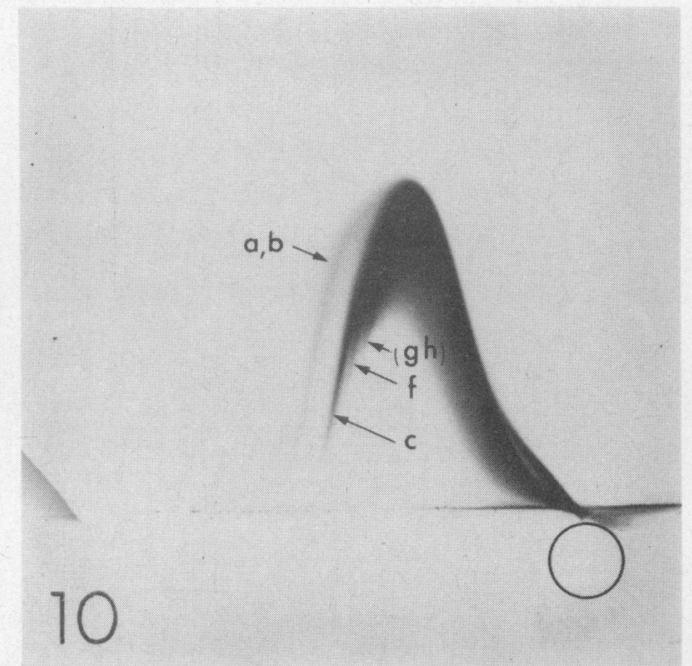

10

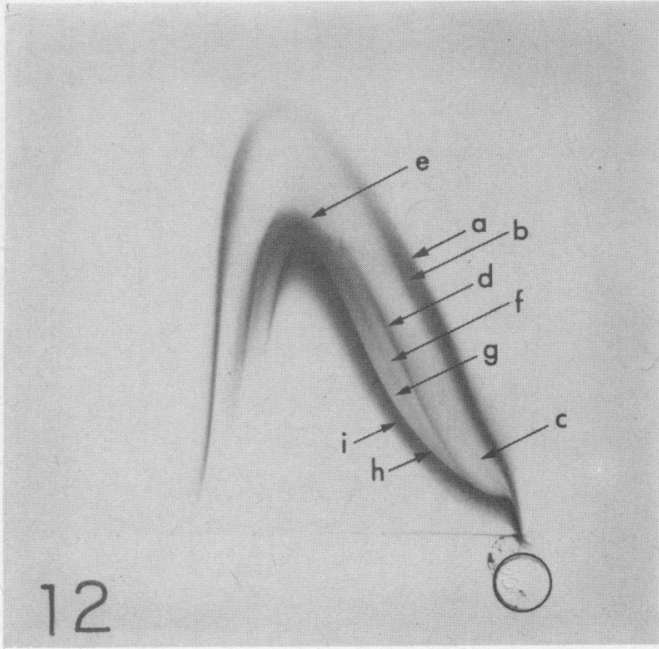




\section{PLATE 3}

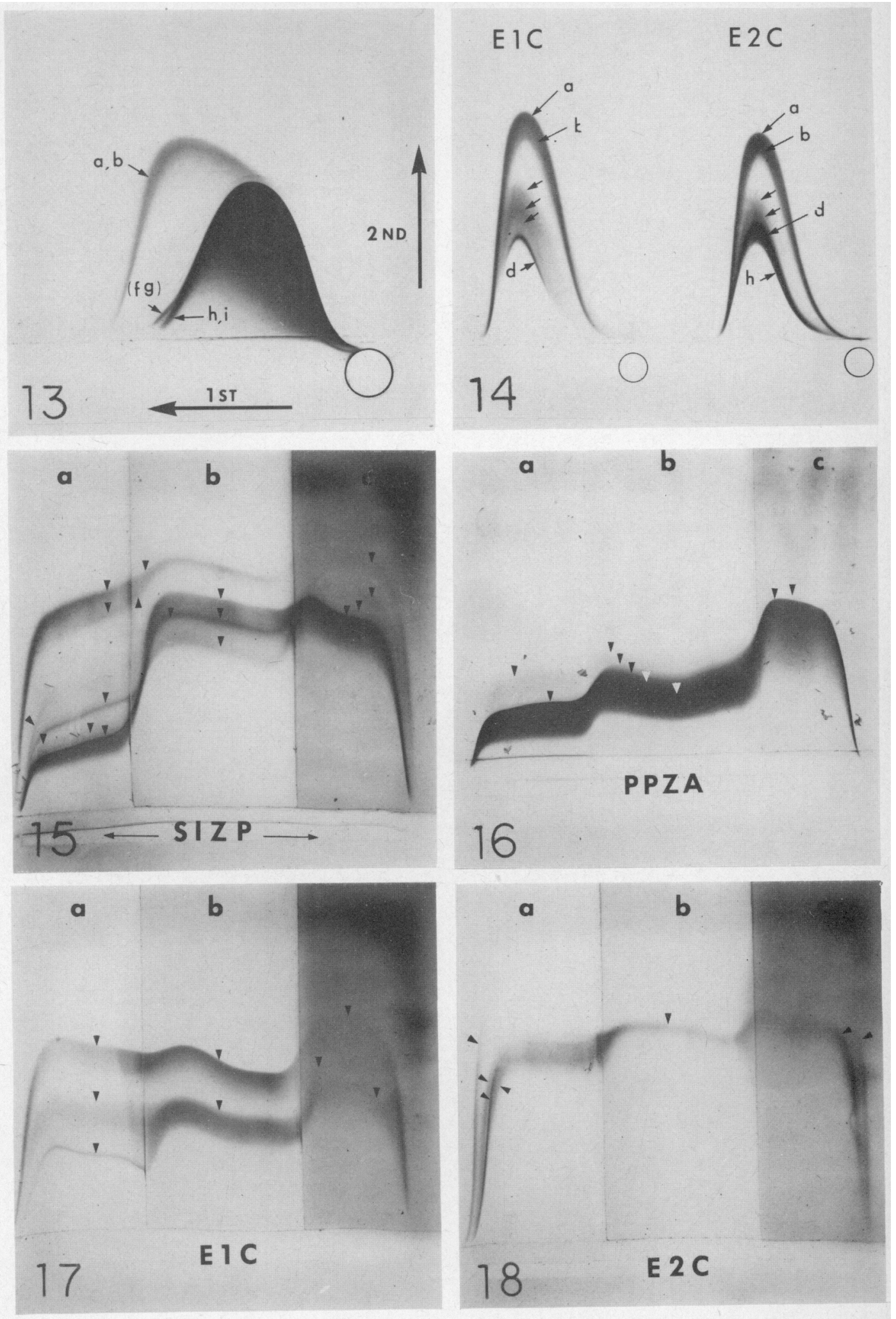




\section{PLATE 4}
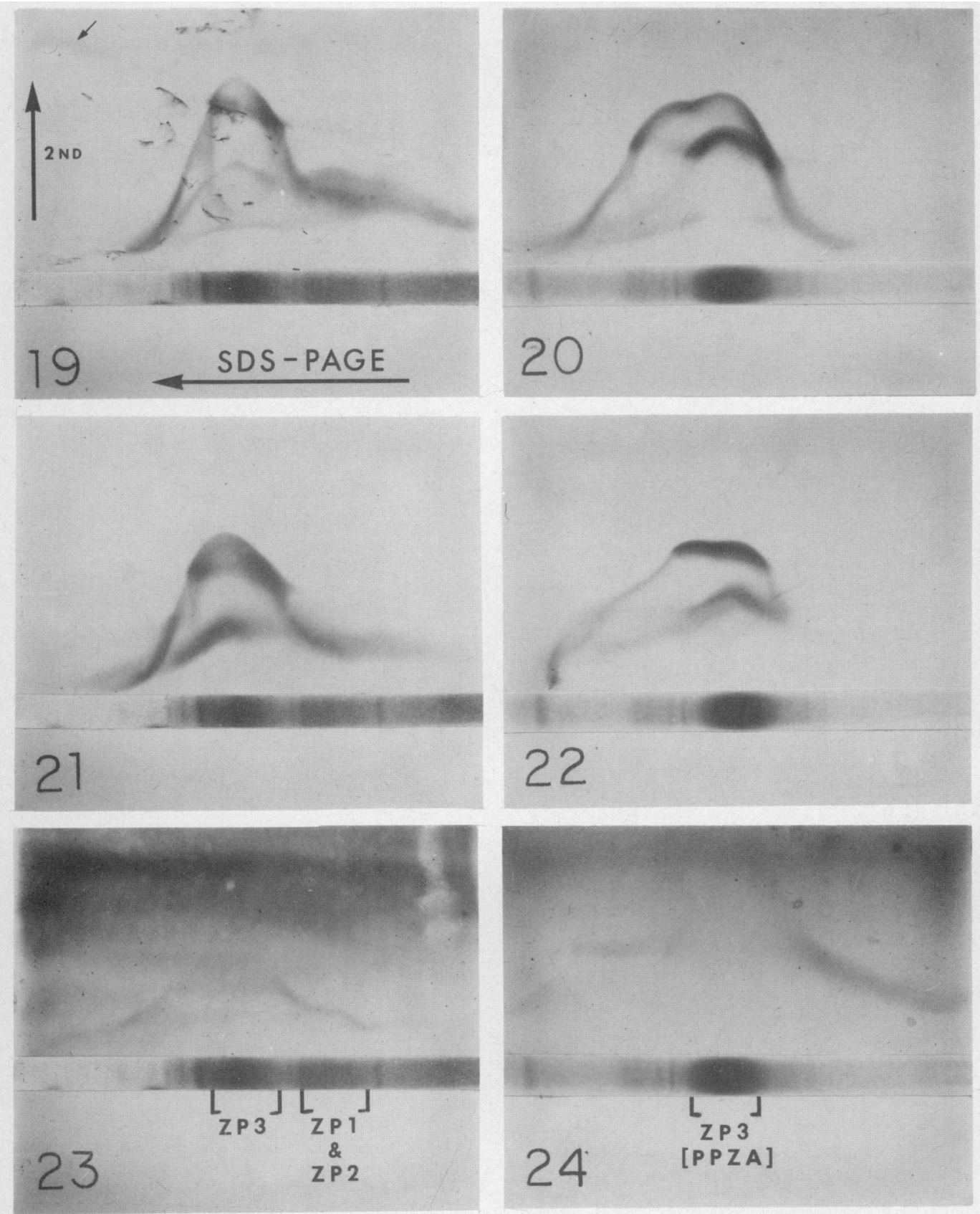
arcs, respectively, produced in the reaction between anti-PPZA serum and SIZP, were common in reactions between this antiserum and ZP3-E1C (arcs a, b, d) and ZP3-E2C (arcs a, b, d, h; Pl. 3, Fig. 14). The remaining precipitin arcs formed in these last two reactions had no counterpart in the reaction of this antiserum with SIZP.

\section{Line immunoelectrophoresis}

In attempts to ascertain the number of common antigens recognized in the various zona preparations by the three antisera, line immunoelectrophoresis studies were undertaken. As expected, the numbers of precipitin bands detected by line immunoelectrophoresis (Table 2) were generally fewer than the numbers of precipitin arcs detected in the comparable reaction using 2-D

\section{PLATE 3}

Two-dimensional and line immunoelectrophoresis of various pig zonae pellucidae samples into gels containing zona antibodies. For 2-D immunoelectrophoresis plates (Figs 13 \& 14) firstdimension electrophoresis was for $3 \mathrm{~h}$ at $90 \mathrm{~V}$ and second-dimension electrophoresis was for 24 $h$ at $35 \mathrm{~V}$. For line immunoelectrophoresis plates (Figs 15-18), antibody gels ' $a$ ', ' $b$ ' and 'c' contained $2 \%$ anti-PPZA serum, $2 \%$ anti-SIZP serum and $3 \%$ anti-IZP serum, respectively. Electrophoresis was conducted for $24 \mathrm{~h}$ at $35 \mathrm{~V}$ from bottom to top (anode) of plate. Arrows indicate precipitin bands resolved in each reaction.

Fig. 13. Electrophoresis of PPZA $(21 \mu \mathrm{g})$ into $2 \%$ anti-PPZA serum. Five precipitin arcs $(\mathrm{a}, \mathrm{b}$, $(\mathrm{fg}), \mathrm{h}, \mathrm{i})$ are resolved. The precipitin arc labelled ' $a, b$ ' and the arc labelled ' $h$, i' each consist of two overlapping precipitin arcs although these are not resolved in the photograph. Arcs ' $f$ ' and ' $\mathrm{g}$ ', as established from tandem studies, fuse to form the single arc labelled (fg).

Fig. 14. Electrophoresis of ZP3-E1C $(5.25 \mu \mathrm{g})$ and ZP3-E2C $(5.25 \mu \mathrm{g})$ into $2 \%$ anti-PPZA serum. Six precipitin arcs are resolved in each reaction. Arcs ' $a$ ', ' $b$ ' and ' $d$ ' can be identified in E1C and arcs ' $a$ ', 'b', ' $d$ ' and ' $h$ ' in E2C. The remaining arcs, identified by arrows, have no counterpart in SIZP as established by tandem-2D immunoelectrophoresis.

Fig. 15. Line immunoelectrophoresis of SIZP $(87.5 \mu \mathrm{g})$ into the 3 zona antisera. A minimum of 2 bands forms reactions of identity in each of the 3 antisera.

Fig. 16. Line immunoelectrophoresis of PPZA $(70 \mu \mathrm{g})$ into the 3 zona antisera. A minimum of 2 bands forms reactions of identity in each of the 3 antisera.

Fig. 17. Line immunoelectrophoresis of ZP3-E1C ( $30 \mu \mathrm{g})$ into the 3 zona antisera. A minimum of 2 bands forms reactions of identity in each of the 3 antisera.

Fig. 18. Line immunoelectrophoresis of ZP3-E2C $(80 \mu \mathrm{g})$ into the 3 zona antisera. At least 1 precipitin band forms a reaction of identity in each of the 3 antisera.

\section{PLATE 4}

SDS-PAGE immunoelectrophoresis. Non-reduced SIZP was subjected to SDS-PAGE and the major zona components resolved as indicated in Fig. 23. Under these conditions ZP1 and ZP2 co-migrate as a single smear at $M_{r}=92000$. The remaining major component constitutes ZP3 $\left(M_{r}=60000\right)$. Labelling in Fig. 23 also applies for Figs 19 and 21 . Non-reduced PPZA was also subjected to SDS-PAGE as indicated and labelled in Fig. 24. Labelling in Fig. 24 also applies for Figs 20 and 22.

Fig. 19. Electrophoresis of SDS-PAGE-resolved SIZP into $2 \%$ anti-SIZP serum.

Fig. 20. Electrophoresis of SDS-PAGE-resolved PPZA into $2 \%$ anti-SIZP serum.

Fig. 21. Electrophoresis of SDS-PAGE-resolved SIZP into $\%$ anti-PPZA serum.

Fig. 22. Electrophoresis of SDS-PAGE-resolved PPZA into $2 \%$ anti-PPZA serum.

Fig. 23. Electrophoresis of SDS-PAGE-resolved SIZP into $8 \%$ anti-IZP serum.

Fig. 24. Electrophoresis of SDS-PAGE-resolved PPZA into $8 \%$ anti-IZP serum. 
Table 2. Precipitin bands detected by line immunoelectrophoresis when various porcine zona antigen preparations are electrophoresed into the different zona antisera

\begin{tabular}{ccccc}
\hline & \multicolumn{4}{c}{ Zona antigen preparation } \\
\cline { 2 - 5 } $\begin{array}{c}\text { Antiserum } \\
\text { against }\end{array}$ & SIZP & $\begin{array}{c}\text { PPZA } \\
\text { (non-SDS-treated) }\end{array}$ & $\begin{array}{c}\text { ZP3-E1C } \\
\text { (SDS-treated) }\end{array}$ & $\begin{array}{c}\text { ZP3-E2C } \\
\text { (SDS-treated) }\end{array}$ \\
\hline IZP & 4 & 2 & 3 & 2 \\
SIZP & 5 & 5 & 2 & 1 \\
PPZA & 7 & 2 & 3 & 4 \\
\hline
\end{tabular}

IZP $=$ intact zona pellucida $;$ SIZP $=$ heat-solubilized isolated zona pellucida; PPZA $=$ purified pig zona antigen; $\mathbf{Z P}=$ zona pellucida.

immunoelectrophoresis (Table 1). Nonetheless, in spite of the overall lower resolution, 1 or 2 common antigens were detected in each of the 4 zona preparations ( 2 for SIZP, PPZA and EIC and 1 for E2C preparations) as established by the reactions of identity formed when each zona preparation was electrophoresed simultaneously into the three antisera (Pl. 3, Figs 15-18).

\section{SDS-PAGE immunoelectrophoresis}

SDS-PAGE of non-reduced SIZP results in the separation of the ZP3 component $\left(M_{r}=\right.$ 60000 ) from the remaining two major zona glycoproteins, ZP1 and ZP2, which co-migrate as a single diffuse band at $M_{r}=92000$ under these conditions (Pl. 4, Figs 19, $21 \& 23$ ). Consequently, following the second-dimension electrophoresis of such resolved SIZP into zona antibodycontaining gels, data regarding antibody recognition with respect to these separated zona components can be obtained.

Electrophoresis of SIZP into an anti-SIZP-containing gel revealed that this antiserum predominantly recognized ZP3 as indicated by the height, intensity, and number of precipitin arcs over the ZP3 region of the gel. A lower level of antibody response also occurred with the higher molecular weight zona components (ZP1 and ZP2). A low molecular weight zona component was also recognized as indicated by a single faint precipitin arc (small arrow) over the bottom region of the gel (Pl. 4, Fig. 19). Electrophoresis of PPZA into this antiserum resolved a minimum of 5 precipitin arcs which peaked over this $60000 \mathrm{M}_{\mathrm{r}}$ component. Two of these precipitin arcs were slightly skewed toward the lower molecular weight end of the gel (Pl. 4, Fig. 20).

Electrophoresis of SIZP into an anti-PPZA-containing gel demonstrated that this antiserum reacts primarily with the ZP3 component in SIZP. A minimal level of antibody reactivity with the higher molecular weight zona components was also indicated (P1. 4, Fig. 21). Electrophoresis of PPZA into anti-PPZA revealed at least 5 precipitin arcs which peaked over this component but were skewed toward the low molecular weight portion of the gel (Pl. 4, Fig. 22).

Electrophoresis of SIZP or PPZA into anti-IZP serum resulted in development of a single faint band spanning the entire length of the SDS gel but which peaked over the region of the ZP3 component (Pl. 4, Figs 23 \& 24).

\section{Discussion}

A major feature of the porcine zona system when evaluated by 2-D immunoelectrophoresis as observed in this study and elsewhere (Dunbar \& Raynor, 1980) is the stacking of the precipitin arcs formed following second-dimension electrophoresis of zona antigens into antibody-containing gels. This characteristic pattern results from the minimal migration and subsequently poor resolution of individual zona components following their first-dimensional electrophoresis in agarose. These 
properties suggest that zona antigens have similar electrophoretic mobilities and possess comparable charge densities, probably characterized by a low charge to mass ratio. This poor precipitin arc separation makes pattern interpretation difficult especially for the more complex tandem and intermediate gel 2-D immunoelectrophoretic procedures. Nevertheless, in spite of its obvious limitations, in relation to the zona antigen system, this technique is significantly more sensitive than double diffusion or the more conventional immunoelectrophoretic procedure and useful information regarding zona pellucida antigenicity can be obtained as summarized below.

Dunbar, Wardrip \& Hedrick (1980) indicated that isolated porcine zonae preparations obtained by screening procedures are contaminated with about $7 \%$ non-zona material. However, procedures used to heat-solubilize zonae obtained in this manner probably do not solubilize the contaminating material and, therefore, the resulting SIZP preparations do not contain organ crossreactive antigens (Dunbar \& Raynor, 1980). Consequently, antiserum produced against SIZP is zona specific (Gwatkin \& Williams, 1978; Gwatkin, Anderson \& Williams, 1980; Dunbar \& Raynor, 1980). The zona specificity of the remaining two antisera used in this investigation, antiIZP and anti-PPZA, has previously been demonstrated (Palm et al., 1979; Subramanian et al., 1981). Therefore, precipitin arc patterns resolved in this investigation by use of these three antisera are probably representative of only zona-specific antigen-antibody reactions. Furthermore, since the antisera used were produced against intact zonae (anti-IZP) or solubilized zona preparations obtained under the least disruptive conditions available (anti-SIZP and anti-PPZA), the resulting precipitin arc patterns should be representative of antigens comparable to or minimally altered from their status within the intact zona.

The results in Table 1 indicate that antiserum produced against intact zonae pellucidae (IZP), and therefore the most likely to contain antibodies developed against zona antigens in their native and unaltered configuration within the intact zona, can still recognize 6 antigens in heat-solubilized zonae preparations (SIZP). Thus, the antigenic integrity of at least 6 native zona components is maintained following solubilization by heat. A similar conclusion was recently reported by Nayudu, Freemann \& Trounson (1982) who indicated that heat-solubilization of porcine zona has a minimal apparent effect on altering zona antigen structure. Furthermore, from the present investigation, two of these antigens, ' $e$ ' and ' $f$ ', continue to be recognized in each of the antigen preparations, even after exposure to SDS. These data indicate that at least 2 of the 6 antigens present in intact zonae and recognized in SIZP by this antiserum are associated with the $60000 \mathrm{M}_{\mathrm{r}}$ zona component (ZP3) and are stable to conditions required for antigen purification. This recognition of antigenic determinants associated with the ZP3 component by anti-IZP serum is further supported by SDS-PAGE immunoelectrophoretic studies which demonstrate the peaking of a precipitin arc over the ZP3 region of the gel following second-dimension electrophoresis of SIZP or PPZA into this antiserum (PI. 4, Figs 23 \& 24).

Eight zona antigens are recognized in the reaction between SIZP and its respective antiserum, 5 or 6 of which are associated with the $60000 \mathrm{M}_{\mathrm{r}}$ component, ZP3 (Table 1). This large number of precipitin arcs resolved in the reaction between anti-SIZP serum and PPZA suggests that the $60000 \mathrm{M}_{\mathrm{r}}$ component may be more immunogenic than the two other zona components (ZP1 and ZP2) contained in SIZP, and is additionally supported by the observation in SDS-PAGE immunoelectrophoretic studies (P1. 4, Fig. 19) that this antiserum predominantly recognizes the ZP3 component in SDS-PAGE gels. However, such findings may also be indicative of quantitative differences among the three major components present in SIZP. The same 4 antigens, 'a', 'b', 'd', 'f', are recognized in the SDS-treated ZP3-E1C and ZP3-E2C preparations, but the ' $\mathrm{d}$ ' antigen is not detected in the more native PPZA preparation. Therefore, with respect to this antiserum, the nonSDS-treated antigen preparations are not identical antigenically and exposure of SIZP to SDS has resulted in at least a minimal antigenic alteration of the ZP3 macromolecule. This is consistent with the significant loss of zona antigen activity after exposure of SIZP to SDS and heat. Although the same 4 components are distinguished in the E1C and E2C preparations, the ' $d$ ' and ' $f$ ' precipitin arcs in the E2C preparation are consistently more intense (PI. 2, Fig. 11), perhaps indicative of a 
quantitative difference in these two antigenic components between the two samples. Since the E2C preparation is more highly enriched in charge isomers of more neutral pI than is the E1C preparation, the ' $d$ ' and ' $f$ ' precipitin arcs may represent antigens associated with the more neutral charge isomers that are predominant in the $\mathrm{E} 2 \mathrm{C}$ preparation.

Reaction of anti-PPZA serum with its homologous antigen PPZA resulted in development of a minimum of 5 precipitin arcs (Table 1). Electrophoresis of SDS-PAGE-resolved PPZA into this antiserum (Pl. 4, Fig. 22) also revealed at least 5 precipitin arcs which peaked over the ZP3 component. The multiple precipitin arcs produced in these reactions emphasize the antigenic complexity of the ZP3 macromolecule and are probably a result of a zona-specific but polyclonal antiserum recognizing different antigenic determinants on the same macromolecule. Several of these antigenic determinants associated with ZP3 must also be common to other zona pellucida components (possibly ZP1 and/or ZP2) as suggested by the increased number of precipitin arcs obtained when PPZA antiserum is reacted against SIZP (Table 1) and by the low level of antibody reactivity observed with the higher molecular weight zona components in SDS-PAGE immunoelectrophoretic studies (Plate 4, Fig. 21). Collectively, these data suggest that the 3 major porcine zona macromolecules share common antigenic determinants.

Differences in precipitin arc patterns for reactions of the anti-PPZA serum against the 3 antigen preparations are similar to those with the SIZP antiserum and indicate that treatment of SIZP with SDS has altered the antigenicity of the ZP3 macromolecule (Table 1). Such modifications in the macromolecule are detected by the presence of different antigens in the SDS- and non-SDS-treated antigen preparations. Also, the preparation of PPZA resulted in an alteration in the charge density of antigens ' $a$ ' and ' $b$ ' as indicated by the slight shift of these two precipitin arcs toward the anode (Pl. 3, Fig. 13; Pl. 2, Fig. 10). However, the antigenicity of these two antigens was not significantly altered because the 2 precipitin arcs continued to fuse with their counterparts in the SIZP and ZP3-E1C/ZP3-E2C preparations during tandem 2-D immunoelectrophoresis.

The double peak produced by two of the precipitin bands formed after SDS-PAGE immunoelectrophoresis of PPZA into anti-SIZP (Pl. 4, Fig. 20) or anti-PPZA (Pl. 4, Fig. 22) may be indicative of the microheterogeneity of the ZP3 macromolecule due to degrees of glycosylation (Bjerrum, 1977). This finding would be in agreement with the study of Hedrick \& Wardrip (1981) suggesting that the carbohydrate side chains of various charge isomers within a given zona family possess different primary structures. Anti-PPZA serum also distinguishes differences between the ZP3-E1C and ZP3-E2C preparations, not only by variations in precipitin arc intensity observed between the two preparations (Pl. 3, Fig. 14), but also by the detection of different precipitin arcs in each preparation (Table 1 ).

While these experiments demonstrate that multiple antigens are associated with intact zonae, heat-solubilized zonae, PPZA and ZP3-E1C/ZP3-E2C, line immunoelectrophoresis studies indicate that 1 or 2 antigens are common to each of these zona preparations (Pl. 3, Figs 15-18). Such studies further confirm that the antisera to IZP and SIZP contain antibodies directed against the $60000 \mathrm{M}_{\mathrm{r}}$ zona component (ZP3). The precipitin band fusion patterns obtained in line immunoelectrophoresis investigations also support the concept that the individual antisera are recognizing multiple antigenic determinants on the same macromolecule. For example, simultaneous electrophoresis of SIZP into anti-SIZP and anti-IZP serum gave 3 precipitin bands in the anti-SIZP reaction fusing to form a single band in the anti-IZP reaction ( $\mathrm{Pl}$. 3, Fig. 15). This fusion pattern suggests that each antiserum is recognizing a single zona macromolecule (i.e. antigen) but the antiSIZP serum can detect 3 antigenic determinants on the molecule while the anti-IZP serum responds to only 1 of these determinants. Therefore, the multiple precipitin arcs/bands detected in these various immunological reactions are probably not indicative of the existence of large numbers of individual zona macromolecules but instead represent the recognition of multiple antigenic determinants present on a considerably fewer number of major zona components. The fact that multiple antigenic determinants can be recognized on a single major zona macromolecule by a particular antiserum has previously been indicated by the numerous precipitin arcs resolved in 2-D immuno- 
electrophoresis studies involving anti-PPZA serum and PPZA (Pl. 3, Fig. 13). Whether such individual antigenic determinants are representative of the individual charge isomers comprising the various major zona families of glycoproteins remains to be established.

This work was supported in part by NIH grant No. HD 10189.

\section{References}

Bjerrum, O.J. (1977) Immunochemical investigation of membrane proteins. A methodological survey with emphasis placed on immunoprecipitation in gels. Biochim. Biophys. Acta 472, 135-195.

Dunbar, B.S. \& Raynor, B.D. (1980) Immunochemical characterization of porcine zona pellucida antigens. Biol. Reprod. 22, 941-954.

Dunbar, B.S., Wardrip, N.J. \& Hedrick, J.L. (1980) Isolation, physiocochemical properties and macromolecular composition of zona pellucida from porcine oocytes. Biochemistry, N.Y. 19, 356-365.

Dunbar, B.S., Liu, C. \& Sammons, D.W. (1981) Identification of the three major proteins of porcine and rabbit zonae pellucidae by high resolution twodimensional gel electrophoresis: comparison with serum, follicular fluid, and ovarian cell proteins. Biol. Reprod. 24, 1111-1124.

Garrels, J.I. (1979) Two-dimensional gel electrophoresis and computer analysis of proteins synthesized by clonal cell lines. J. biol. Chem. 254, 7961-7977.

Gwatkin, R.B.L. \& Williams, D.T. (1978) Immunization of female rabbits with heat-solubilized bovine zonae: production of anti-zona antibody and inhibition of fertility. Gamete Res. 1, 19-26.

Gwatkin, R.B.L., Anderson, O.F. \& Williams, D.T. (1980) Large scale isolation of bovine and pig zonae pellucidae: chemical, immunological and receptor properties. Gamete Res. 3, 217-231.

Hedrick, J.L. \& Wardrip, N. (1981) Microheterogeneity in the glycoproteins of the zona pellucida is due to the carbohydrate moiety. J. Cell Biol. 91, 177a.

Henderson, L.E., Oroszan, S. \& Konigsberg, W. (1979) A micromethod for complete removal of dodecyl sulfate from proteins by ion-pair extraction. Analyt. Biochem. 93, 153-157.

Kroll, J. (1973a) Tandem-crossed immunoelectrophoresis. Scand. J. Immunol. 2, 57-59.

Kroll, J. (1973b) Line immunoelectrophoresis. Scand. J. Immunol. 2, 61-67.

Laemmli, U.K. (1970) Cleavage of structural proteins during the assembly of the head of bacteriophage T4. Nature, Lond. 227, 680-685.

Laurell, C.B. (1965) Antigen-antibody crossed electrophoresis. Analyt. Biochem. 10, 358-361.
Lowry, O.H., Rosebrough, N.J., Farr, A.L. \& Randall, R.J. (1951) Protein measurement with the Folin phenol reagent. J. biol. Chem. 193, 265-275.

Nayudu, P.L., Freemann, L.E. \& Trounson, A.O. (1982) A quantitative indirect immunofluorescent assay for zona pellucida antibodies. J. Reprod. Fert. 65, 67-75.

O'Farrell, P.H. (1975) High resolution two-dimensional electrophoresis of proteins. J. biol. Chem. 250, 40074021.

Palm, V.S., Sacco, A.G., Syner, F.N. \& Subramanian, M.G. (1979) Tissue specificity of porcine zona pellucida antigen(s) tested by radioimmunoassay. Biol. Reprod. 21, 709-713.

Sacco, A.G. (1981) Immunocontraception : consideration of the zona pellucida as a target antigen. In Obstetrics and Gynecology Annual, Vol. 10, pp. 1-26. Ed. R. M. Wynn. Appleton-Century-Crofts, New York.

Sacco, A.G. \& Palm, V.S. (1977) Heteroimmunization with isolated pig zonae pellucidae. J. Reprod. Fert. 51, 165-168.

Sacco, A.G., Yurewicz, E.C., Subramanian, M.G. \& DeMayo, F.J. (1981) Zona pellucida composition: species cross-reactivity and contraceptive potential of antiserum to a purified pig zona antigen (PPZA). Biol. Reprod. 25, 997-1008.

Subramanian, M.G., Yurewicz, E.C. \& Sacco, A.G. (1981) A specific radioimmunoassay for the detection of a purified porcine zona pellucida antigen (PPZA). Biol. Reprod. 24, 933-943.

Vaitukaitis, J., Robbens, J.B., Nieschlag, E. \& Ross, G.T. (1971) A method for producing specific antisera with small doses of immunogen. J. clin. Endocr. Metab. 33, 988-991.

Weeke, B. (1973a) Crossed immunoelectrophoresis. Scand. J. Immunol. 2, 47-56.

Weeke, B. (1973b) General remarks on principles, equipment, reagents and procedures. Scand. $J$. Immunol. 2, 15-35.

Wood, D.M. \& Dunbar, B.S. (1981) Direct detection of two cross-reactive antigens between porcine and rabbit zonae pellucidae by radioimmunoassay and immunoelectrophoresis. J. exp. Zool. 217, 423-433.

Received 15 July 1982 